\title{
Structural Analysis in Shoufengsi Area of Tananao Complex, Eastern Taiwan
}

\author{
Gong-Ruei $\mathrm{Ho}^{1}$ and Wei $\mathrm{Lo}^{2, *}$ \\ ${ }^{1}$ Graduate Institution of Engineering Technology-Doctoral, National Taipei University of Technology, Taipei, Taiwan, R.O.C. \\ ${ }^{2}$ Department of Materials and Mineral Resources Engineering, National Taipei University of Technology, Taipei, Taiwan, R.O.C.
}

Received 16 October 2014, revised 13 May 2015, accepted 15 May 2015

\begin{abstract}
The subduction and collision boundaries of the Eurasia and Philippine Sea Plates in the Taiwan mountain belt expose a NE-trending coherent crustal section in the Tananao Complex. This study investigates the structures in three dimensions in the Shoufengsi area, which is located in the middle section of the Tananao Complex to understand the Taiwan orogeny mountain building processes. Detailed geological mapping and structural analyses shows the eastward shortening associated with metamorphism indicative of three deformation events. Three sets of axial plane foliation S1, S2, and S3 can be recognized by Type-1 and Type-3 fold interference patterns. Different structural characteristics can be further revealed in five domains based on domain analysis. Each domain shows the superposed process characteristics. Synthetic structural mapping and microstructure examination analyses on the Shoufengsi area show that NE-trending isoclinal folds and axial D1 and D2 plane foliation events represent shortening deformation and NW-trending crenulation cleavage. Normal D3 event faults display the gravity collapse deformation. These observations are consistent with shortening to extension stage predictions during Eurasia and Philippine Sea Plate collisions.
\end{abstract}

Key words: Shoufengsi, Interference pattern, Transposition cycle

Citation: Ho, G. R. and W. Lo, 2015: Structural analysis in Shoufengsi area of Tananao Complex, eastern Taiwan. Terr. Atmos. Ocean. Sci., 26, 557-569, doi: 10.3319/TAO.2015.05.15.01(TT)

\section{INTRODUCTION}

Regional structures with compositional layering are frequently used to analyze the structural style of foliations. These structures are one of the most spectacular products of mountain building processes. In the subduction and collision boundaries between the Eurasia and Philippine Sea Plates around Taiwan, many foliations are records of how those deformation paths are superposed. Detailed geological mapping and structural analyses shows that at least three sets of foliation have different structural styles (Wang and Yang 1979; Yang 1981; Lin 1986; Zhan 1990) and different attitudes exist (Stanley et al. 1981; Chen and Yang 1985; Jiao 1991; Lo 1993). These ductile/brittle structures include the recumbent folds with vertical stress from the mountain collapse process (Lee 1997; Yeh 2004). These studies have attempted to elucidate the subduction/collision processes around Taiwan. However, geometric, kinematic and petrologic predictions of each study differ dramatically. The

\footnotetext{
* Corresponding author

E-mail:lowei93@ntut.edu.tw
}

details are described in Ho (2007).

Understanding the development of macroscopic folds in multi-deformed terrains requires identification of their layering related to the deformation history and can be recorded in structures at microscopic and mesoscopic scales. Although it is challenging, many studies have demonstrated that regional structure examinations can characterize complex tectonic events. For instance, folds may initiate at low angles or sub-parallel to the transport direction and mesoscopic fold vergence provides a geometric means for macroscopic fold reconstruction. The fold vergence would change along a macroscopic fold axis (Alsop and Holdsworth 1999; Liotta 2002). Identifying interference patterns is an effective way of reconstructing the fold development sequence (Brogi 2006). In the orogeny process different structural styles are typically associated at different structural levels (Malavieille 1993). Mesoscopic folds can only give relative sequences. To improve the correlation of multi-deformed Tananao Complex with orogenic history we should carefully combine each relative sequence. 
In this situation numerous examples illustrate multideformed structures. In the Acadian orogeny foliations with the same attitudes are not necessarily related to the same deformation event. An orogeny may produce several sets of foliations (Ham and Bell 2004). In a mineral growth study of several regional folding events (Bell et al. 2003), some folds may have been formed early during the deformation processes. Late foliations forming with sub horizontal orientations transect most regional folds. These younger foliations can be rotated by reactivating the folded layering as they form. Previous studies have shown that which orogenic history these deformations belong to is uncertain. One possible solution to solve this problem is fabric analysis which can be used to discuss the relationship between microscopic and mesoscopic investigations.

Fabric analysis is therefore important to understand deformation history and how these foliations are involved in different collision and subduction tectonic fabrics. This study focuses on foliation, one of the most spectacular fabrics of orogeny in crustal rocks. For example, using minor folds and cleavage/bedding relationships, one can locate the regional antiform or synform folds (Powell 1992). The foliation transposition cycle has been typically applied to illustrate the orogenic process. Microstructural mapping of thin sections can also be used to identify the relationships between folding, shearing and foliation development (Aerden et al. 2010). Tobisch and Paterson (1988) used the transposition cycle to establish the areal extent of domains with different progressive deformation histories in southeastern Australia and western Nevada. These examples indicate that the relationship between foliations and regional structure has strong potential in correlating regional structures to foliations along the orogen. The study area, the Shoufengsi, is located at the core of the Tananao Complex with well-exposed outcrops where the Shoufengsi river channel cuts through the regional strike of structures. A wealth of foliations and multiple deformation events exist in this area. Thus, a structural study in the Shoufengsi can clarify the orogenic events that generated these fabrics. In this study foliations of orogen are identified and their meanings can place the evolution of the Tananao Complex within a reasonable context.

Several recent studies based on geochronological dating and structural arguments have identified three age generations in the Tananao Complex (Lan et al. 2008, 2009; Yui et al. 2009, 2012). We can try to connect every fold and cleavage during the same deformation event. Analyzing mesoscopic scale structural evolution in the Shoufengsi area and its tectonic implications will increase our understanding of multi-deformation.

\section{GEOLOGICAL SETTING}

\subsection{The Lithology and Metamorphic Grade of the Tananao Complex}

The Tananao Complex, distributed along the eastern flank of Taiwan's Central Range, extends from Wuyenchiao, roughly $3 \mathrm{~km}$ south of Suao, through the west of Hualien and Yuli to $40 \mathrm{~km}$ southwest of Taitung (Fig. 1). The north-south length of this metamorphic terrain is approximately $240 \mathrm{~km}$ and the east-west width is $25 \mathrm{~km}$ in the north (Nanao and Tailuko), $20 \mathrm{~km}$ in the middle (Yuli), and $10 \mathrm{~km}$ in the south (Taitung). The entire Tananao Complex area is estimated about $4600 \mathrm{~km}^{2}$. The Tananao Complex is the oldest geological and tectonic unit in Taiwan and can be divided into two metamorphic belts using the Shoufeng Fault (Yen 1963) (Fig. 1). It consists of black schist, metasandstone, quartz schist, meta-chert, meta-conglomerate, meta-limestone, gneiss, meta-granite, green schist, glaucophane schist, amphibolite, and serpentine rock types. (Ogasawara et al. 1936; Yen 1960; Chen 1963; Wang 1982; Lee 1984; Lo 1993). In these studies the researchers accept that folding and faulting are very common in The Tananao Complex. Folds are transected by axial plane cleavages and faults are usually exposed as ductile shear zones. Few studies have tried to correlate structures in different sequences. As a result of complex tectonic events and difficulties in geological investigations, the development sequences in many regions remain unknown. For instance, some macroscopic folds/faults with wavelengths of several kilometers are hard to examine using mesoscopic observations. New developed foliations are superposed onto older deformed structures. Schistosity is therefore often recognized as bedding planes. The primary problem is that superimposed outcrops are obscured

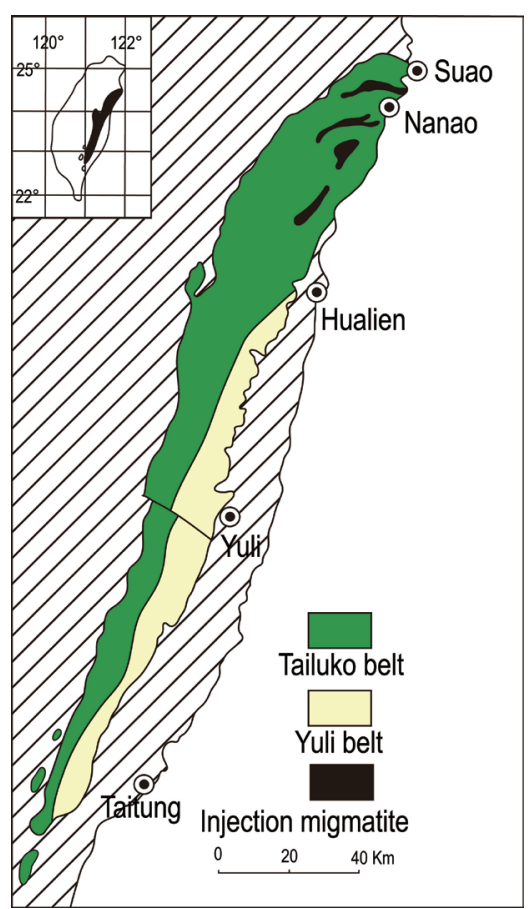

Fig. 1. The paired metamorphic belts of the Tananao Complex area. The geological map was modified after Yen (1963). 
and the structural sequences are difficult to determine. This study therefore examined many minor folds, mostly parasitic folds, which are usually formed in the Shoufengsi. These mesoscopic or microscopic folds will be examined to clarify the structural history of the Shoufengsi.

\section{FIELD INVESTIGATIONS AT THE SHOUFENGSI}

Outcrops in the Shoufengsi contain quartz-mica schist and marble of the Tananao Complex. The geological route map (Fig. 2) shows the lithology distribution and structures, including faults and folds, by detailed geological investigation. Rock units in the Shoufengsi area can be divided into two parts at the Shoufengsi and Dakuasi junction. The rock units in the western part are characterized by marble, quartzmica schist and chlorite schist and those in the eastern part mainly by quartz-mica schist and metachert with well-developed foliation (Fig. 2). Fold interference patterns are commonly observed in outcrops in this region (Figs. 3a, b) and the folds usually grow as asymmetrically (Fig. 3c). Faults develop as ductile shear zones (Figs. 3d, e) and brittle normal faults (Fig. 3f). Three ductile shear zones, each $2-\mathrm{km}$ wide, exist upstream of the Shoufengsi. The ductile shear zone shear plane is roughly parallel to the well-developed S2 foliation. The widely distributed S2 is the main foliation in the Shoufengsi area. We can recognize the later crenulation cleavage $\mathrm{S} 3$ superposed onto $\mathrm{S} 2$ and the previous cleavage $\mathrm{S} 1$, which is influenced by $\mathrm{S} 2$ in the microlithon domain. Multiple deformations exist according to the field observations. The S3 with gentle dip can be observed (Figs. 3g, h). The rock also has a well-developed transposition structure with rootless folds and lenticular rock layers, indicating strong deformation superposed in this area. The Shoufengsi is an excellent site for studying the structural evolution of these superposed fabrics.

Foliations are superposed together after strong transposition. We try to recognize that from different superposed features in several domains. The Shoufengsi area characteristic is that different domains have dominant foliations. Many S2 or S3 measurements can be identified here, although we are not sure of S1, because of the late deformation influence. Their strikes and dips are recognized as: S2, $\mathrm{N} 30^{\circ}-50^{\circ} \mathrm{E}, 30-50^{\circ} \mathrm{NW}$; S3, N15 $5^{\circ} 30^{\circ} \mathrm{W}, 20-35^{\circ} \mathrm{NE}$, respectively. Most of $\mathrm{S} 1$ were deformed by $\mathrm{S} 2$ strong superposed process. S2 developed as axial plane cleavage with a series of asymmetric folds with wavelength of about $3-5 \mathrm{~m}$ with a vergence to the east (Fig. 3c). The S3 foliation locally is emerged from the Dakuasi (Fig. 2) and developed with a top-to-east shortening folds (Fig. 3g) and a recumbent fold with a fold wavelength of $3-5 \mathrm{~m}$ (Fig. 3h). An additional normal fault is exposed with D3. The existence of recumbent folds and normal faults may result from very strong vertical stress (Fig. 3f).

Generally, the strong S2 guides the structural style and rock distribution in this region. The residual crenulation $\mathrm{S} 1$ can only be found in the microlithon domain of S2 cleavage, indicating that the previous structure is still observable in microscopic analysis. The $\mathrm{S} 3$ foliation is locally exposed along the Shoufengsi. Some ductile zones can also be observed in the Shoufengsi area. There are two kinds of shear zones, Sa shear zone with thrust motion along S2 (Fig. 3d) and $\mathrm{Sb}$ shear zone with left-lateral strike slip motion along S3 (Fig. 3e). The Sa developed with a shear structure and is easily traced in the geological investigation and geological

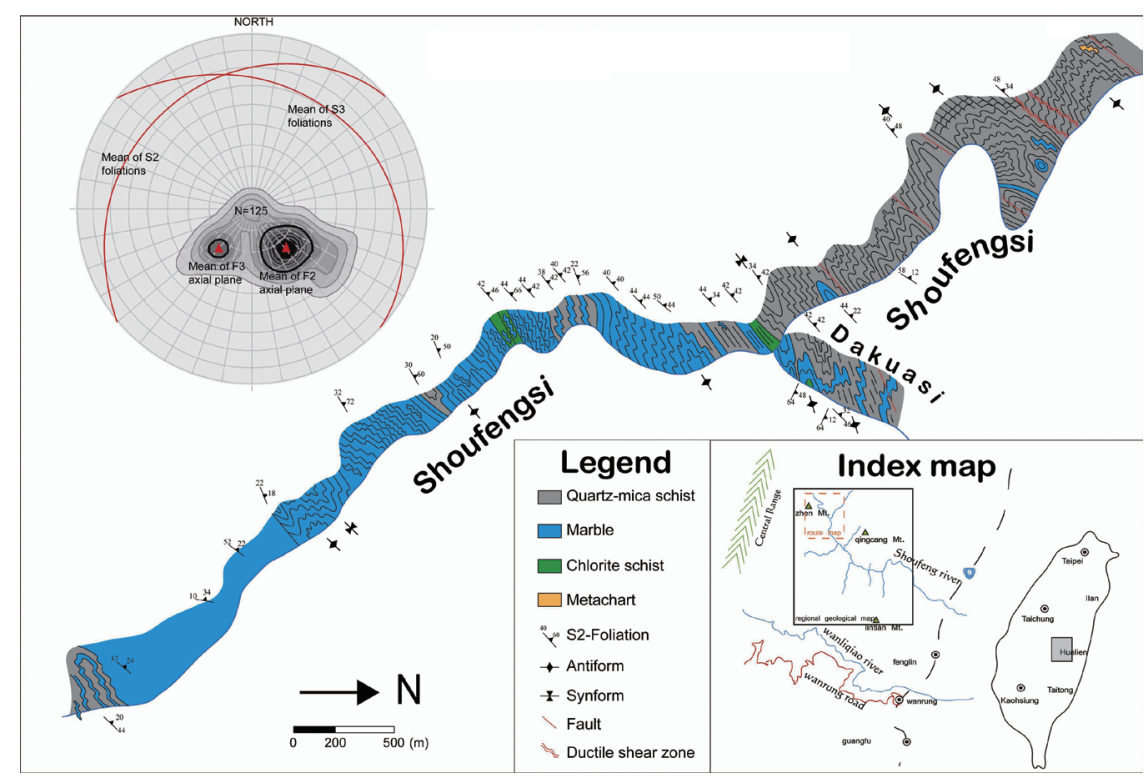

Fig. 2. The geological route map of the Shoufengsi area shows the location, rock type and mesoscopic structures. The index of Fig. 2 is the dashed orange frame. 

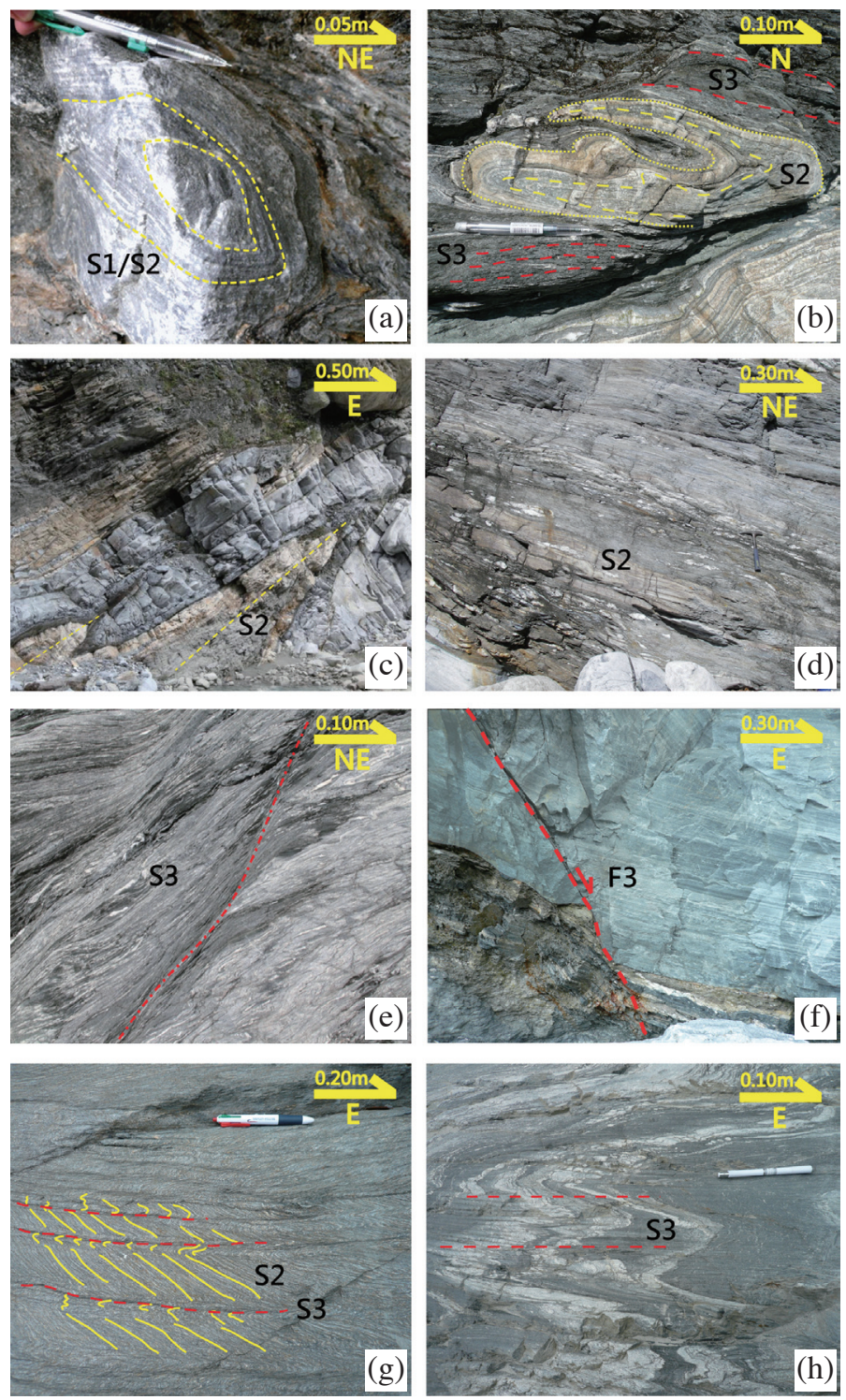

Fig. 3. The mesoscopic structures of the Shoufengsi area. (a) and (b) are Type- 1 and Type-3 interference pattern located on the boundary of marble and schist. (c) NE-trending fold with well-developed S2 foliation located at the junction of the Qiakansi and the Dakuaisi. (d) The highly deformed ductile shear zone paralleled S2 with a top-to-northeastern shear plane. We cannot measure the offset with such highly deformed shear zone. (e) The ductile shear zone reflects left-lateral strike slip motion along the S3 foliation. (f) F3 Normal fault in the Qiakansi. (g) Folded S2 foliation dips east with gentle dipping S3 axial plane cleavage. (h)The recumbent fold developed S3 axial plane cleavage.

map (Fig. 4). The meso- and microscopic structure observation shows a consistent shear direction and a sense that reflects thrust motion along the main foliation (Ho 2007). The Sb shear zone is locally superposed onto S2 (Fig. 3g). The meso- and microscopic structure observation shows an $\mathrm{S}-\mathrm{C}$ band that reflects left-lateral strike slip motion along S3 foliation. Comparing the Sa shear zone with Sb shear zone, there are many shear structures (mantled-porphyroclasts, mica-fish, pressure shadow...etc.) that can be investigated that reflect higher deformation. After field analysis we can recognize the relationship between each foliation. The key question is the final results of their superposed structure. Because these complex structures have influenced the struc- tural style in different ways in different areas, domain analysis is conducted and each characteristic is described below.

\section{DOMAIN ANALYSIS}

When rock layers are seated at a simple deformed area with a lower structural level, the rock is usually deformed into cylindrical folds. The axis of each fold is nearly parallel to the macroscopic structures with an immobile cleavage attitude. Although the foliation fan distribution can only be observed near the fold axis, with most axial plane cleavages and intersection lineations remaining parallel. Such a regional structure is structurally homogeneous and the method is 
essential for detail structural studies in complex deformed areas. In particular this method is used to establish structurally homogeneous domains and interference relationships in areas of complex folding. This is an effective way for tracking rock layers (McClay 1987).

Conversely, when deformed rock is formed by repeating non-cylindrical folds or conical folds, deformation is only homogeneous locally in the separated domain, with consistent fold axes in each domain. The structure is very complex, with visible fold interference patterns and refolding structures especially in a multi-deformation area. Because lineations, foliations and all folds are irregular in the Shoufengsi region, the field region division with a homogeneous structure is extremely important in this multi-deformation area (McClay 1987).

This study applied the following criteria to differentiate the various domains: (1) areas with a consistent particular shear zone orientation generation; (2) areas with a particular foliation plane consistent orientation; (3) areas with a consistent fold axis orientation; and (4) areas distinguished by their rock layer distribution. Based on these criteria, the region can be divided into five domains (Fig. 4) via different shear zone, foliation, fold axes, and rock type deformations.

Domain I consists of chert and quartz mica schist and contains three sets of foliations and north-bearing fold axes. Some shear structures are locally recognized. Domain II is mainly composed of a thick layer of marble that only exposes one set of foliation and NE/SW-bearing fold axis. Domain III has a well-developed Sa shear zone and is parallel to S2 foliation (Fig. 4). Each of Sa shear zones distributed within $2 \mathrm{~km}$. Domain IV and V have variable attitudes of foliations in the eastern section and can be separated by duc- tile shear zones that are locally superposed on S2 and reflect left-lateral strike slip motion along the $\mathrm{S} 3$ foliation (Fig. 3e). Due to the structural complexity of the Shoufengsi area, domain analysis can help clarify the structural style of each domain. That is, domain analysis provides a way to divide a complex rock mass into five simpler domains. As each domain has its own characteristics, we assume that each domain is structurally homogeneous. Under such assumption the analyses results for different domains can be compared.

To identify different generations in foliation development, the foliation microtectonics must be evaluated. We suggest that there are three sets of well-defined, easily identified foliations. Domain I has three well-developed sets of foliations indicating three tectonic events. An earlier crenulation cleavage, $\mathrm{S} 1 / \mathrm{S} 2$, is preserved within $\mathrm{S} 3$ microlithons while $\mathrm{S} 3$ carves mineral locally without penetrative minerals (Figs. 5a, b). Domain II shows a mosaic texture within the calcites (Fig. 5c). We can observe weak, S1/S2 foliations, especially on the chlorite schist and marble margins. Domain III has well-developed continuous S1/S2 cleavage with new muscovite and elongated quartz (Fig. 5d). S3 is not visible. In Domain IV, the S1, S2, and S3 foliations are well preserved in the matrix. $\mathrm{S} 1$ is commonly rotated by $\mathrm{S} 2$ in the microlithons (Fig. 5e). There are some ductile shear zones developed with $\mathrm{S} 2$, locally influenced the texture of $\mathrm{S} 1 / \mathrm{S} 2$ (Figs. 5a, e). S3 is generally subhorizontal and developed without penetrative minerals (Fig. 5f). Domain V is a well-developed crenulation cleavage from S2 and S3 (Fig. $5 \mathrm{~g}$ ). The $\mathrm{S} 1 / \mathrm{S} 2$ is rare; $\mathrm{S} 3$ is well-developed in gentle attitude without penetrative minerals observed (Figs. 5g, h). Figures $5 \mathrm{~g}$ and $\mathrm{h}$ also show the crenulation cleavage development by partitioning the deformation into progressive

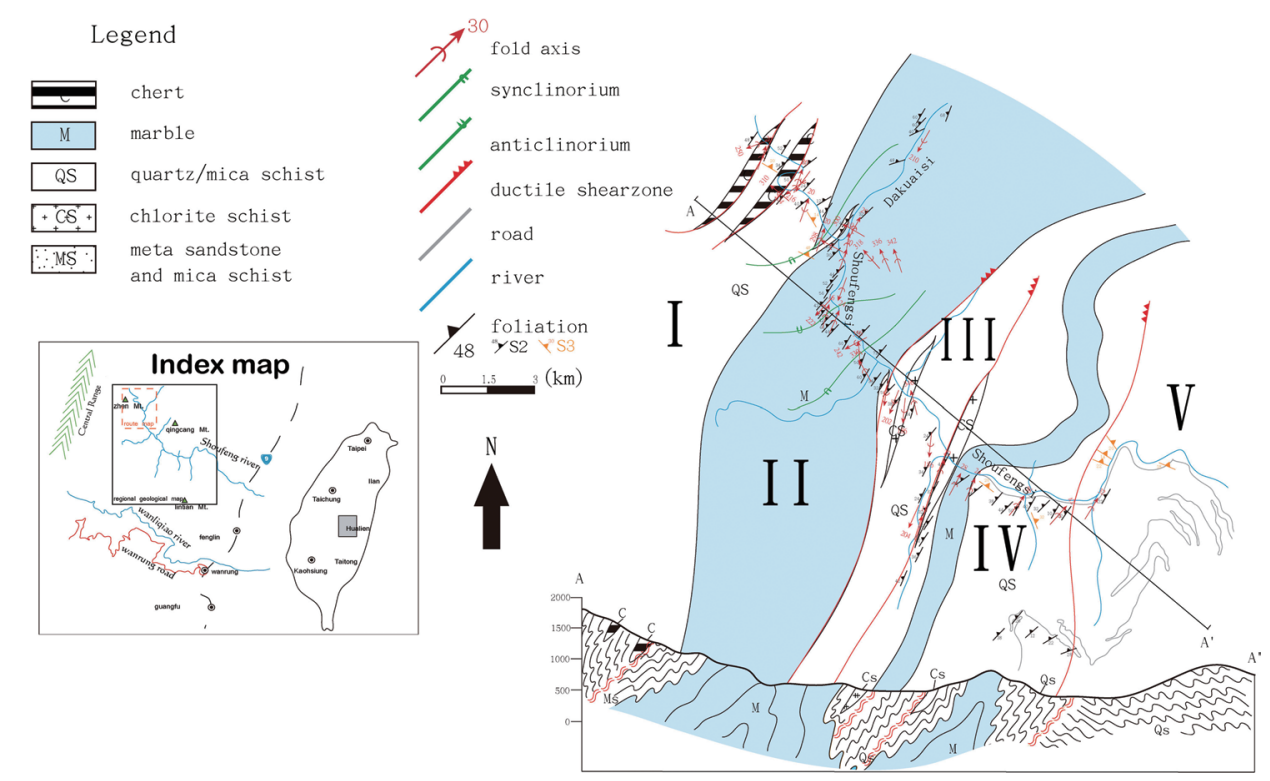

Fig. 4. The regional geological map and profiles in the Shoufengsi area. Domains, regional fold axes and foliations are shown. The index of Fig. 4 is the big and black frame. 

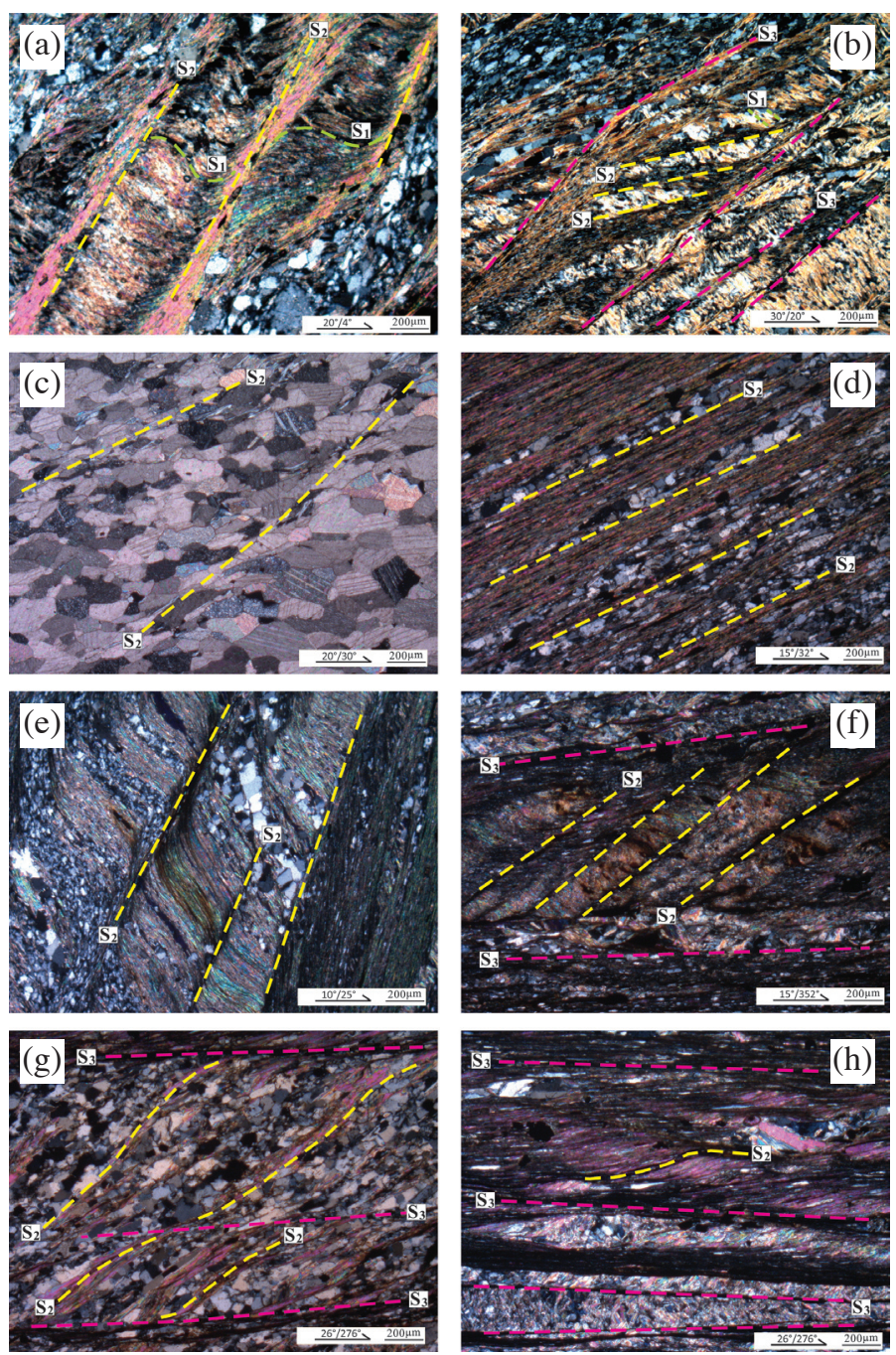

Fig. 5. The micrographs of the Shoufengsi area. The scale and the orientation of stretching lineation are labeled: (a) the S1 and S2 foliations on Domain I. The newly generated S2 grew with muscovite. (b) The S2 and S3 foliations on Domain I. The composition layer of S2 foliation is welldeveloped in crenulation cleavage; S3 was slightly oblique with D3 deformation. (c) The micrograph of Domain II. We can only observe one weak S2 fabric. (d) The typical S2 continuous cleavage of Domain III. (e) The typical S2 crenulation cleavage of Domain IV. (f) The S2 and S3 foliations on Domain IV, S3 located on the rim with NW-trending attitude. (g) The crenulation cleavage of S2 and latest S3 foliations of Domain V. The microlithon of muscovite and quartz is S2, and the cleavage domain is S3. (h) The S3 foliation of Domain V, which dictated main foliation to NWtrending foliation without penetrative mineral.

shearing zones.

Based on above observation and analysis, the study area in the Tananao Complex can be divided into five domains. Field investigation shows that $\mathrm{S} 1 / \mathrm{S} 2$ and $\mathrm{F} 2$ are dominated structures in the western section (from Domain I to IV). Microtectonic analysis indicated that $\mathrm{S} 1$ is identified from the microscopic analysis (Figs. 5a, b), and rarely observed from the mesoscopic analysis. The boundary between Domain I and II is lithological; S1/S2 is the only foliation existed in Domain II of marble layers (Fig. 5c). Domain III separates Domain II and IV by well-developed ductile zone that is parallel to S2 foliation. From S2 to S3, there is a gradual change between Domain III and V (Figs. 5d, e, f, and g). S3 and F3 are the main structures in the eastern Domain
$\mathrm{V}$, which developed gradually in S2 deformed crenulation cleavage (Figs. 5g, h).

\section{REFOLDING ANALYSIS}

Among the fold interference patterns, Type- 1 and Type- 3 are easily observed in these study areas. Type- 1 (Fig. 3a) interference patterns are distributed upstream of the Shoufengsi and Type-3 interference patterns are distributed upstream of the Dakuaisi (Fig. 3b). These interference patterns are located along the boundaries of marble, chlorite schist and quartz-mica schist deposits (Fig. 2). The interference patterns differ among the five domains (Table 1). Because of the various structures superposed on domains 
and because $\mathrm{S} 1$ is usually overprinted by $\mathrm{S} 2$ or $\mathrm{S} 3$, some previous fabrics can also be observed locally on domains (Type-1 interference patterns in Domains I and IV). Based on a previous study, the Shoufengsi area is characteristic of three superposing deformation sets. We call it D1, D2, and D3. We can identify them as S2, S3, and F2, F3. S1 and $\mathrm{F} 1$ are recognized only by their microscopic texture or mesoscopic fold interference patterns. Table 1 shows the typical structural characteristic of each domain. Domain I and IV have S1/S2 and S3 foliations and 2 sets of fold axes, forming the Type-3 interference pattern. Domain II has a major set of S1/S2 foliation and a NE-trending fold axis, forming a simple fold. Domain III has various fold axes and S1/S2 foliation, such that the waving fold exists. Domain $\mathrm{V}$ has gentle S3 foliation, with another set of NE-trending fold axis, such that a recumbent fold and Type-1 interference pattern exist (Table 1). Because the various fold axes formed on Domain I, three penetrative deformation events can be identified. The first deformation event, D1, is only seen in pre-existing $\mathrm{S} 2$ cleavage fabrics. The second deformational event, D2, is widespread and contains fabrics with a series of asymmetric folds. The third deformational event, D3, is accompanied with horizontal recumbent folds and in- tersectional lineations in a gravitational event (Fig. 3h).

Refolding analysis is an effective method for identifying deformations and the orogenic history of this area. Previous studies used different metamorphic events and different methods to document various foliations. (Wang and Yang 1979; Wang and Lu 1981; Lin et al. 1984; Stanley et al. 1981; Faure and Natal'in 1992; Yeh 2004). Predecessor studies indicated that S3 can only be observed in the east slope of the Tananao Complex. In respect for this study we have observed S3 in Domain I, IV , and V, and the dominated S2 in Domain I, II, III, and IV. We believe that these folds formed via at least three deformation events that affected the Tananao metamorphic complex, including $\mathrm{S} 1$, which is only observed in the microlithon domain, $\mathrm{S} 2$, a penetrative cleavage, and S3, the youngest oblique-to-bedding and differentiated cleavage. As the Tananao Complex characteristics reveal, every domain has its own dominate foliation, even in the superposed area. We can correlate every foliation with different structures (e.g., S2 of isoclinal fold and ductile shear zone, and S3 of normal fault and recumbent fold) and build the correlation models of the Tananao Complex. This study brings some light to establishing a method for structural correlation in the Tananao Complex.

Table 1. Structure characteristics of different domains. Data of S1, S2, S3, F2, and F3 are shown in the lower hemisphere stereo nets. The red dots show fold axes. The contour diagrams show poles of foliations and the great circle denotes average foliation.

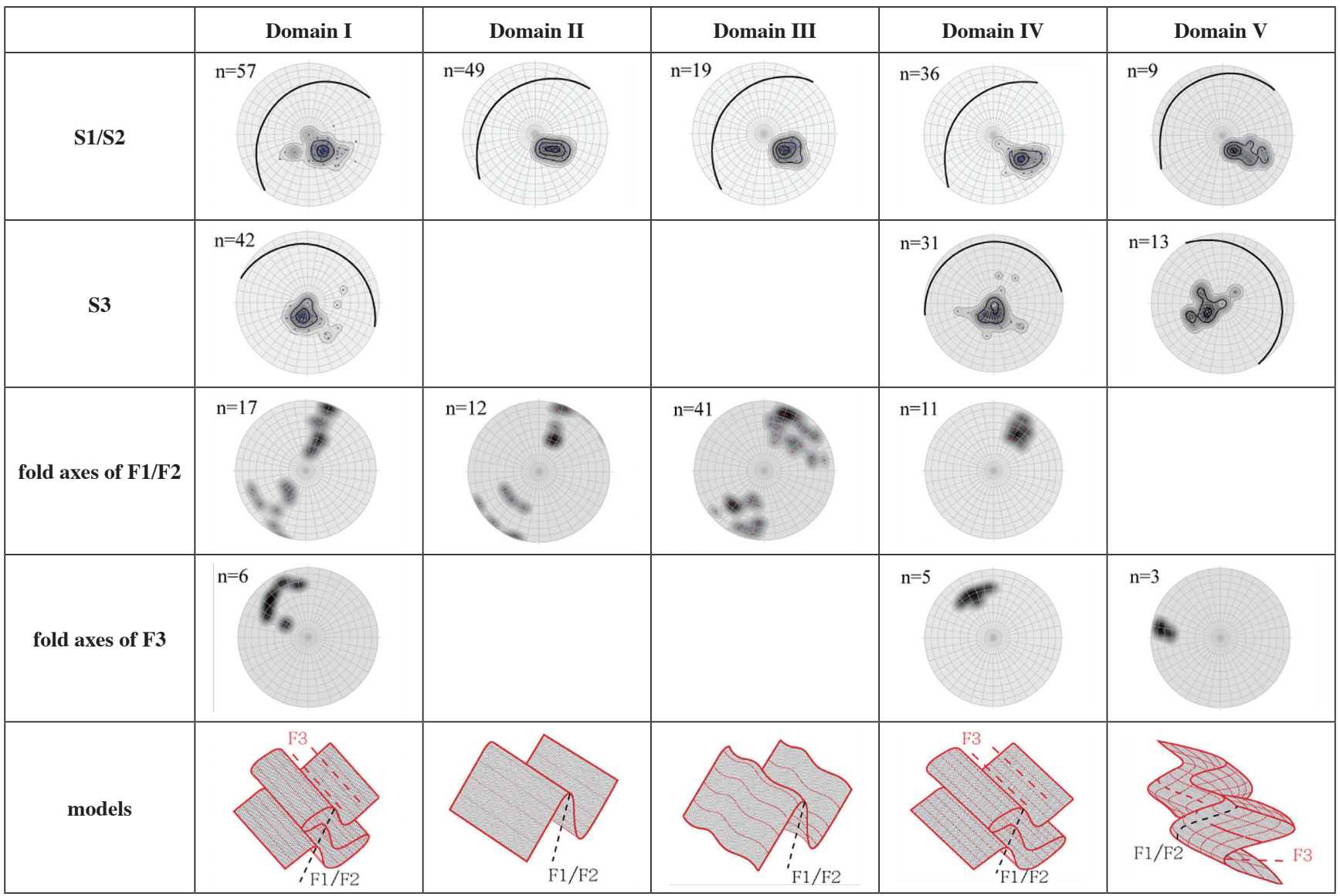




\section{DEFORMATION HISTORY}

Among the D1, D2, and D3 deformation structures in various domains in this area, the D2 folds and foliation are the predominant structures. One can identify the latest D3 deformation via the well-developed Type-1 interference patterns. The earliest D1 fabric was commonly destroyed by D2 with moderate dipping folds (Fig. 3c) or D3 sub-horizontal axial plane cleavage (Fig. 3h).

\subsection{Ductile D1 Deformation}

The first deformation phase, D1, is associated with the first foliation S1, with the axial plane of F1 folds. Because it was destroyed by the later D2 deformation, D1 deformation is difficult to identify. That is, it can only be found at the limbs of the D2 folds, which deformed the original D1 layers. During the strong D2 deformation, D1 fabrics were deformed in the microlithon domains (Figs. 5a, b).

\subsection{Ductile D2 Deformation}

D2 deformation is the main deformation event related to major orogeny. The D2 structures are well-developed in this area, leading to D2 east-vergence isoclinal folding at different scales (Figs. 3c, 5c, d, e, and f). The D2 folds are characterized by a serious of tight folds with sinuous axial surfaces and a new set of S2 foliations (Fig. 6a). Many similar folds and isoclinal folds can be investigated. Throughout the study area, S2 is typically gentle to moderately dipping and has various relationships with S1 (Fig. 6a). These relationships have been used to identify mesoscale D2 structures in the region. $\mathrm{S} 2$ ranges from axial plane cleavage to D2 folds. The D2 folds are the common folds on the mesoto macroscopic scale in the Shoufengsi area. D2 folds are steeply inclined in the hinges of D3 recumbent folds. D3 folds are typically shallow to moderately inclined at the limbs. Figures $6 \mathrm{c}$ and d show that the folded $\mathrm{S} 2$ is deformed by F3. Therefore, the typical Type-3 interference pattern in the EW profile is identified as dominant $\mathrm{S} 3$ foliation and the partial S2 foliation (Fig. 6e).

\subsection{Ductile to Brittle D3 Deformation}

The D3 deformation involves recumbent folds, S3 horizontal axial planes and normal faults developing with a dip of $60-70^{\circ}$ of fault plane (Fig. 3f). The D3 folds are $\mathrm{NW}$-trending recumbent folds that plunge in various north or east directions. We can identify it from the Type- 1 interference pattern (Figs. 3a, 6b). This fold generation is associated with the dominant D3 normal fault throughout the study area. S3 foliation developed with a centimeter-spaced
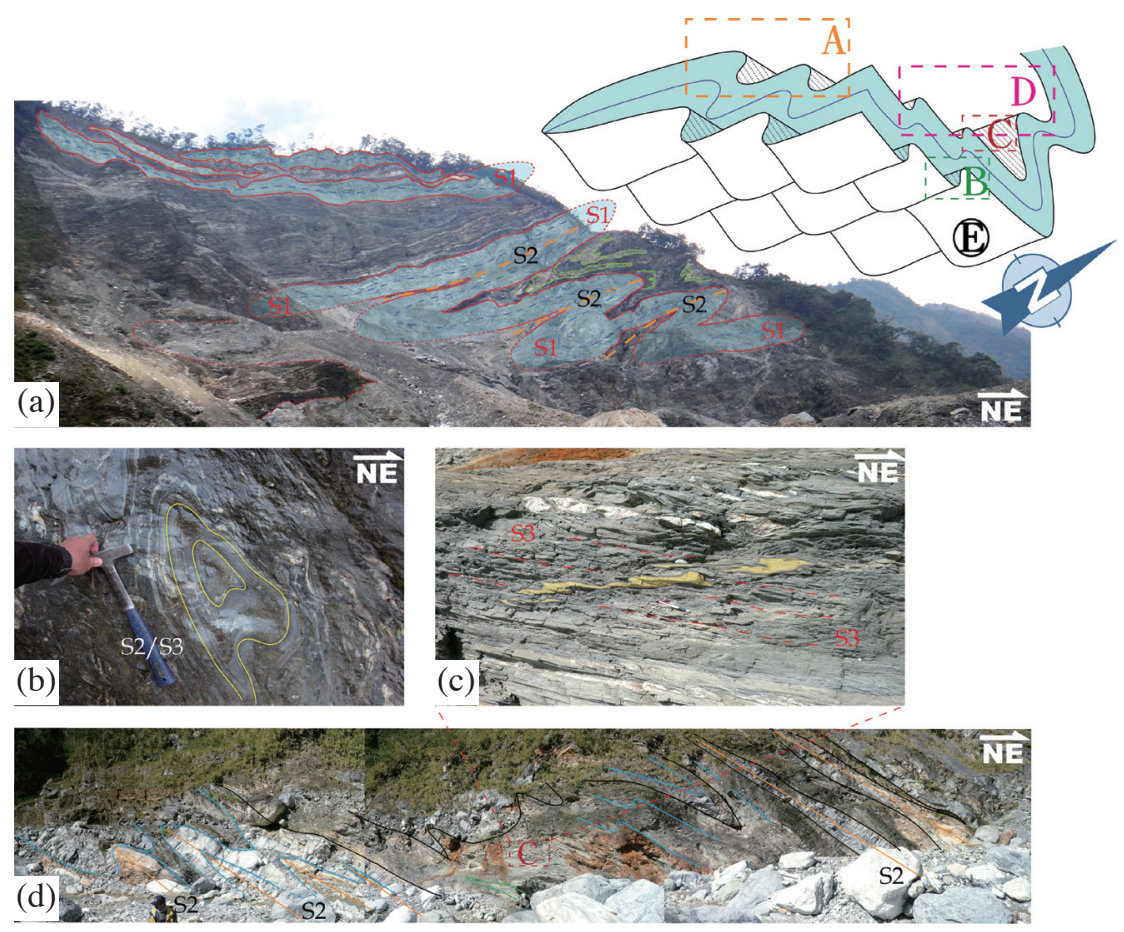

Fig. 6. The mesoscopic refolding structures and deformation models in the Shoufengsi area. (a) 2 sets of fold generations (S1/S2) crest a Type-3 interference refolding outcrop on a mountainside in the Shoufengsi area. (b) Type-1 dome-and-basin interference pattern with S1/S2 foliation deformed by F1/F2 fold structure in a branch of the Shoufengsi. (c) The recumbent fold locally emerged on the NS profile of the Shoufengsi with gentle S3 dip. (d) A series of folds illustrated the transition from S2 foliations by Type-3 interference pattern. (e) The 3D model and the A, B, C, D slices exhibit in the Shoufengsi area. 
fabric, which can be defined by axial plane cleavage and contains partial S2 and S1 fabrics (Figs. 5g, h). The S3 foliation is approximately NW-striking and gently dips $20-35^{\circ}$ (Figs. 3g, h) (Table 1). The recumbent fold and normal fault show that the maximum stress gradually switches to vertical. The switch in the metamorphic regime occurred during D3, leading to a gravitationally normal fault and subhorizontal foliation (Fig. 6e).

\section{DISCUSSION}

\subsection{Transposition Cycle of the Shoufengsi Area}

Various researchers, when confronted with foliations with the same attitudes tried to overcome the problem by designating certain planar structures as transposition or composite foliation (e.g., Turner and Weiss 1963; Williams and Compagnoni 1983; Lagarde and Michard 1986; Tobisch and Paterson 1988) or referred to successive deformations using alphabetical subscripts (e.g., D1 and D2.). In terms of transposition cycle (Tobisch and Paterson 1988), three sets of cleavages exist in the Shoufengsi area; Cycle 1 is used to describe $\mathrm{S} 1$; Cycle 2 is used to describe $\mathrm{S} 2$; and Cycle 3 is used to describe S3. Cycle 0 is the original fabric and is strongly influenced by the later Cycle 1 or any advanced stage. Cycle 2 is a well-developed NE-striking foliation with asymmetric folds and ductile shear zones. Cycle 3 , the latest NW-striking foliation, has the local appearance of the $\mathrm{S} 3$ foliation. Both $\mathrm{S} 1$ and $\mathrm{S} 2$ fabrics can be examined under a microscope. This study can distinguish the three stages of different foliation types (Fig. 7). Stage 1, the initial stage, is locally influenced by the next stage. The crenulation cleavage and/or compositional differentiation is absent or minimally developed. Stage 2 is the predominant crenulation cleavage generated via compression with numerous microfolds in the pre-existing fabric. Secondary cleavage and compositional differentiation is well-developed. Stage 3 is the finite result of progressive deformation. The earlier texture (Stage 1 and 2) was deformed by progressive

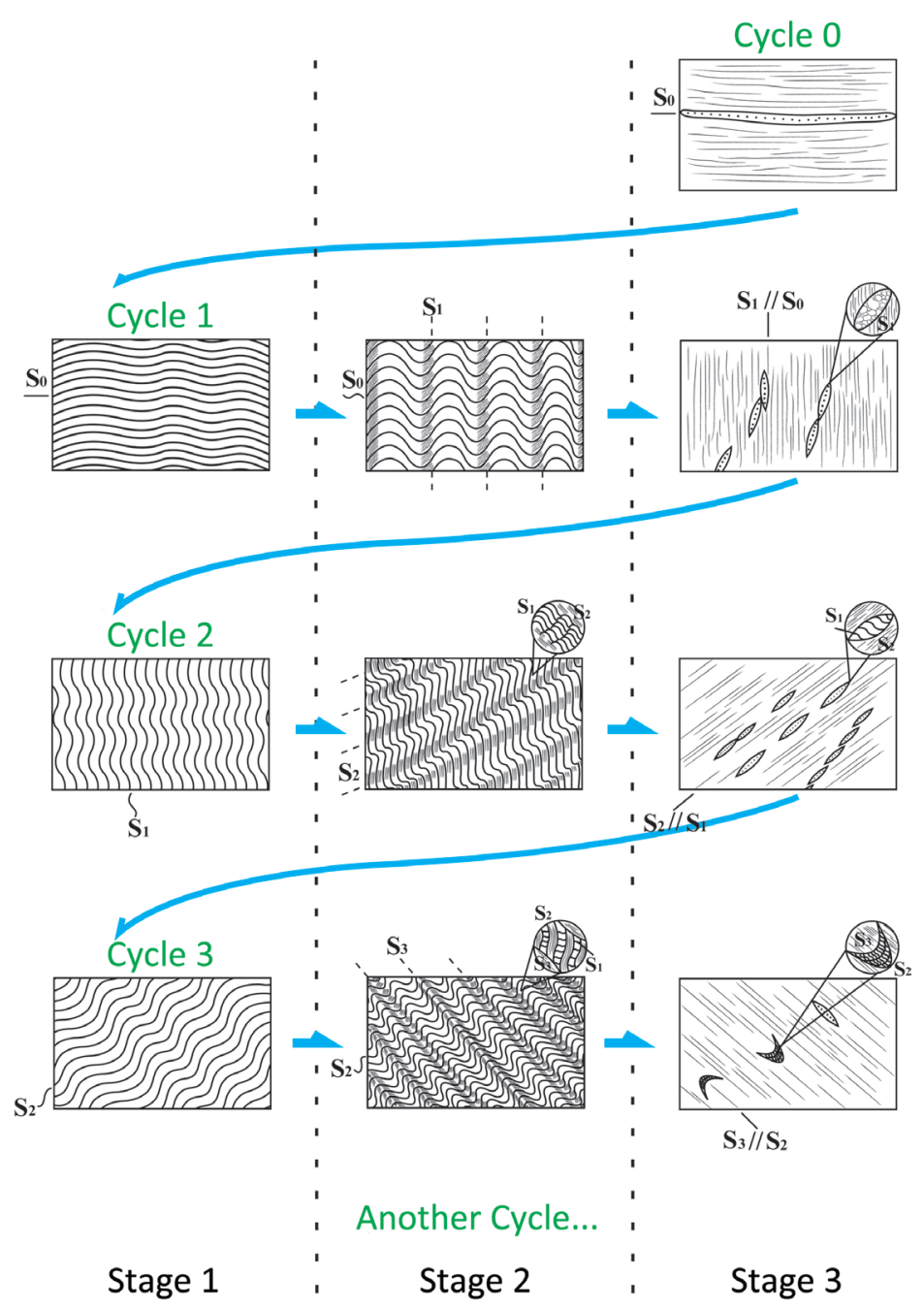

Fig. 7. The foliation transposition cycle in the Shoufengsi area. Stage 1 is bedding fissility and compositional layering; stage 2 is secondary cleavage and compositional differentiation, which developed gradually in crenulation stage; stage 3 is well-developed continuous cleavage. 
deformation and then created a new set of continuous cleavages (Fig. 7). The concept of transposition cycle can help identifying deformed fabrics.

Mapping domains with similar transposition cycles and stages can provide a qualitative manifestation of the deformation processes. Figure 8 shows the location of the transposition cycles on regional scale. Domain I has 3 sets of foliation, from Cycle 2/Stage 3 to Cycle 3. Domain I contains a well-developed refolding structure and interference patterns. Domain II contains Cycle 2 Stage 1 cleavage. The predominant D2 folds with $5-10 \mathrm{~m}$ of wavelength are easily identified as thick marbles. The other characteristics of D2 are the well-developed shear structures in Domain III (Fig. 3d). Notably, D2 formed Cycle 2/Stage 2 crenulation cleavage. The shear structures with displacement indicate that the major S2 foliation shifted the previous S1 fabric. A previous study recognized that the attitude of the Shoufengsi shear plane is $\mathrm{N} 51^{\circ} \mathrm{E}, 36^{\circ} \mathrm{N}$ and the shear sense is thrust with a left lateral strike slip motion (Ho 2007) (Fig. 4). Domain IV is located at the boundary of Cycle 2 and 3. Progressive deformation can be seen easily from Cycle 2/Stage 1 to Cycle 3, forming east-vergence folds with NE-striking axial plane cleavage. Domain V is dominated by Cycle 3 deformation with Stage 1 to 3 development. The axial plane has NW-striking foliation and can be measured microscopically, even in a field investigation. The deformation fabrics composite related to D1/D2/D3 deformation can be divided into different domains. Generally, widespread D2 foliations and locally exposed D3 foliations are observed. D2 is a widely distributed deformation structure and can be identified from Domain I to IV in the Shoufengsi area, as denoted by the triangular symbols in Fig. 8. Domain II exhibits that the degree of deformation of the initial Stage 1 of Cycle 2 gradually increases to the sides. D2 developed with plenty of recrystal quartz and muscovite (Figs. 5a, d, and e) and indicates that the metamorphic grade is under $300^{\circ} \mathrm{C} / 10-15$ $\mathrm{km}$. In the areas of Domain I, IV, V, we can observe latest $\mathrm{S} 3$ accompanied with $\mathrm{F} 3$ fault in mesoscopic analysis (Fig. 3f) and the locally exposed $\mathrm{S} 1$ foliation in microscopic analysis. The D3 developed without penetrative minerals (Figs. 5g, h) and indicates that the metamorphic grade is lower. D2 is the regional structure of the Tananao Complex and D3 reflects the local structure in the eastern Shoufengsi area. All of these observations can be linked to Type- 1 and Type-3 fold interference patterns (Table 1) (Figs. 3a, b). Based on the foliation attitude and shear plane analyses, the direction of the maximum stress is compressional SE-NW of D2 and extensional vertical of D3. It can be considered as the manifestation of the Taiwan arc-continent collision. The dominated D2 and D3 indicate different Penglai orogeny stages. The earlier D1 can be linked to earlier Nanao Orogeny and was completely influenced by the gradual collision between the Luzon Island Arc and the continent of China during the on-going convergence of the Eurasian and Philippine Sea plates.

Based on the rock type in the Shoufengsi area the

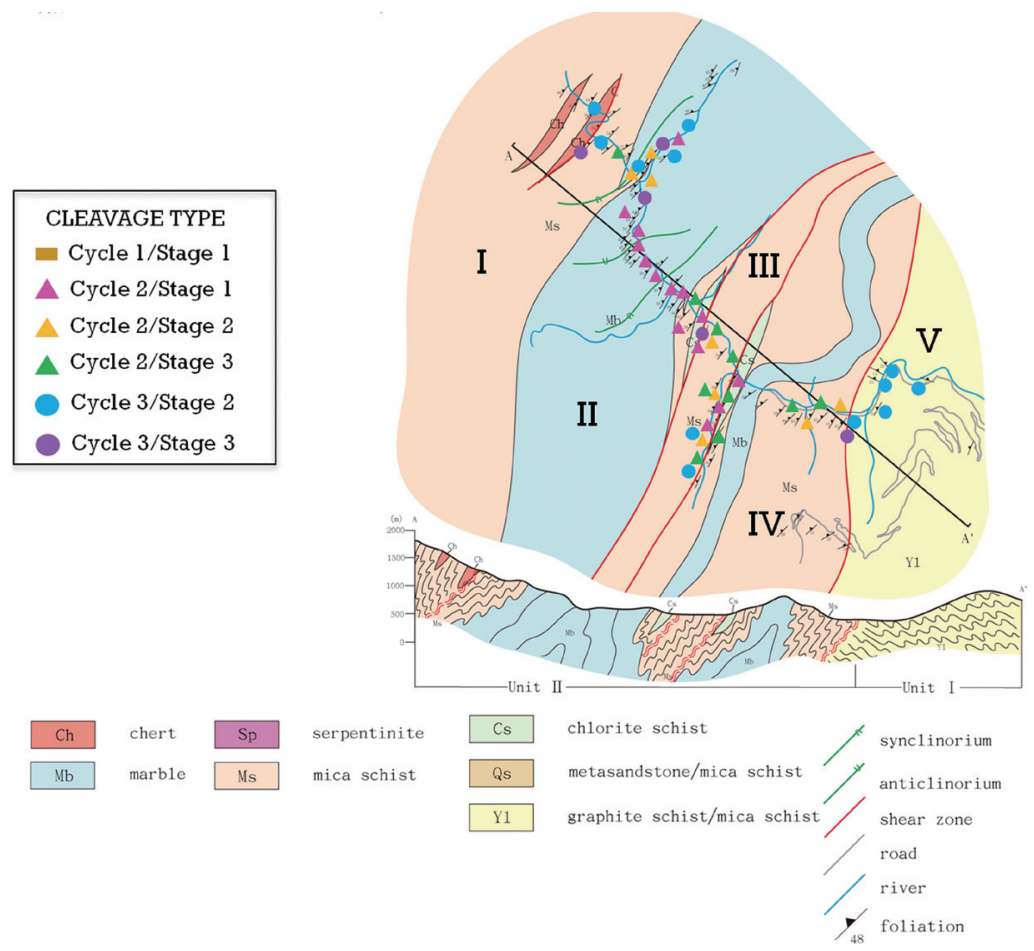

Fig. 8. The distribution map of transposition cycles and stages of the Shoufengsi area. Different color means different stage: rectangle pattern shows $1^{\text {st }}$ cycle; triangle pattern shows $2^{\text {nd }}$ cycle and circle denotes $3^{\text {rd }}$ cycle. 
cleavage mechanism is mostly recrystallization and that in Domains III and V is mostly mechanical rotation. It is speculated that the cleavage in Domain III is affected by shear zone. Domain V is affected by mountain collapse. This study demonstrates that the transposition cycle concept comprises a quite useful method for separating deformation events and identifying the cycle/stage. One deformation event can generate several foliation stages with different morphologic phenomena. Different foliations can also be classified into different cycles/stages. Continuously progressive foliation transposition can form transposition cycles. Differential layering is the feature that can be used to identify these cycles. Foliations are transported progressively so that each foliation cycle can be defined (Johnson and Vernon 1995; Ponce et al. 2013). For instance, differential layering is the key to differentiating a continuous cleavage from a locally carved crenulation cleavage. A new foliation cycle must have been established as a new differential layering. A transposition development cycle is a quite reasonable and observable index in a multi-deformation area.

\subsection{D3 Structural Domain and Tectonic Analysis}

After domain analysis in the Shoufengsi area, the metamorphic complex can be divided into five domains. Generally, one can observe widespread Cycle 2 foliation with D2 tight and isoclinal similar folds. The initial Cycle 2/Stage 1 foliation can be observed in Domain II. The other domains have stronger deformation degree. Cycle 3 foliation with D3 recumbent folds is discovered in Domains I, IV, and V. The transposition cycles and evolutionary histories can be determined from different structural characteristics by domain analysis. The excellent results from this method show that the Shoufengsi area has undergone three major deformations. Thus, the proposed method can be applied to identify Taiwan's orogenic process.

The Shoufengsi area metamorphic complex has experienced the extensional exhumation of late orogenic processes. One can observe a set of gently, NW-striking, Cycle 3 within the recumbent folds and foliation developed in Domains I, IV, and V. These horizontal fabrics imply that the main stress gradually switched to vertical. The switch in the metamorphic regime occurred during D3, including mountain collapse and spreading after orogenic compression cessation. The late orogenic extension processes (i.e., extension that immediately follows crustal shortening and mountain building or sometime later) have been studied. Previous works show that the extension occurred in rift zones or in oceanic crust and also affected wide areas in the continental crust (Malavieille 1993). Orogenic collapse and spreading occurs in the upper portion of a crust and extends in response to gravitational forces and changing conditions with a positive topographic feature. The collapsing crust can no longer support itself and must spread laterally (Maher
1994). Orogenic collapse is wide-spread as shear zones and recumbent folds in the high-deformation-level and normal faults in the low-deformation-level in the middle Central Range (Lee 1997). Based on domain analysis and transposition analysis in this study, mountain collapse influences the eastern slope of the Tananao Complex and its effects are also widely distributed in the Domain I, IV, and V areas in the Shoufengsi area (Table 1) (Fig. 8).

\section{CONCLUSIONS}

Fabric analysis is of great practical utility in unraveling the structural sequence recorded in rocks when rocks change along a unique deformation path under similar metamorphic conditions, which is indistinguishable by other means. Because foliations form under distinct lithologic and metamorphic conditions, the original contact would be overprinted by several metamorphic events. The attitudes of foliations are also influenced by deformations. Therefore, domain analysis is very useful in reconstructing structural evolution. Foliation and fold style analysis are of great value in isolating the superposed layers. The foliation cycle/ stage can be used to establish metamorphic history.

Structural mapping in the Shoufengsi area of the Eastern Central Range has revealed typical fold interference patterns resulting from the superposed D2 NE-trending steeply inclined folds and D3 NW-trending recumbent folds. Such deformation has resulted in synchronous development of Type-1 dome-and-basin and modified Type-3 hook-shaped fold interference patterns throughout the area. Synchronous development of Type- 1 and Type- 3 fold interference patterns can be identified in the profiles where the Shoufengsi meets the Dakuasi. Combining these fold styles and field evidences in several domains, 3D models of the structural evolution show that D1/S1 could be influenced by subsequent deformation (Fig. 9). Where D2 superposes on D1 one can observe a widely distributed Type-3 interference pattern (Fig. 6a). The final D3 deformation deformed previous rock layers and locally developed the Type-1 interference pattern (Figs. 3a, 6b). According to the route map and regional cross section analysis, D1 and D2 formed under compression with the moderate dipping of S1/S2 and D3 developed under extension with gentle S3 dipping. This study also identified some ductile shear zones corresponding to a shortening mechanism developed in D2 and normal faulting (Fig. 3f) corresponding to mountain collapse in D3. These deformations caused a triple-folding geometry in the Shoufengsi area. This study performed structural analysis on the Shoufengsi area in the Tananao Complex and obtained good results for the development of fabrics and fold interference patterns.

Acknowledgements The authors would like to thank the National Science Council of the Republic of China, Taiwan, 


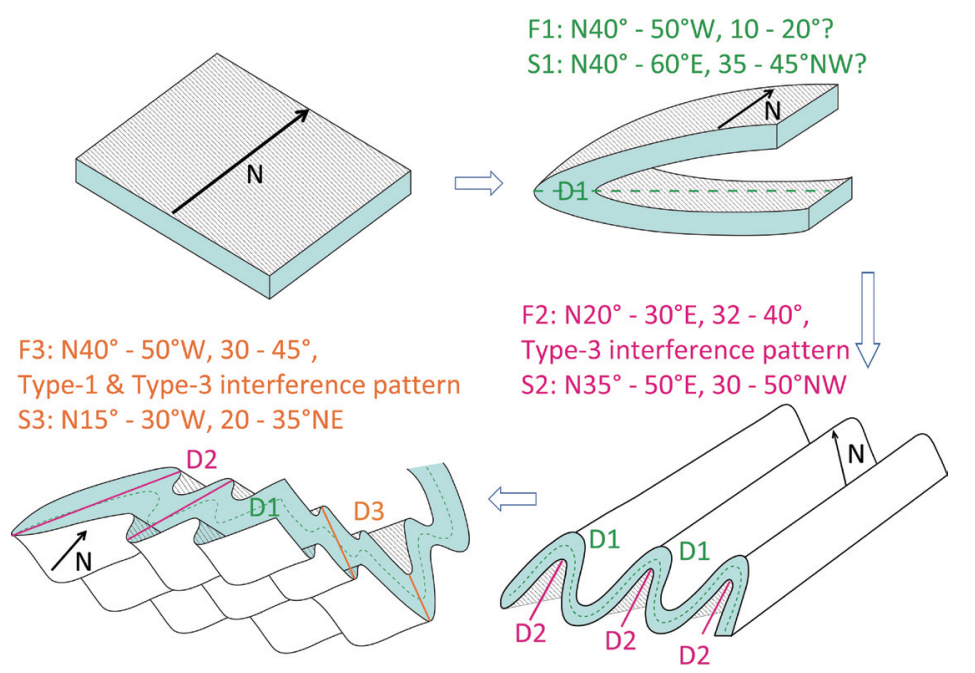

Fig. 9. The 3D model shows the fold interference pattern resulting from the superimposition of structural events. The F1, F2, and F3, indicate fold axes of each generation. The S1, S2, and S3 indicate foliations, and D1, D2, and D3 indicate deformations.

for financially supporting this research under Contract No. NSC-103-2116-M-027-002.

\section{REFERENCES}

Aerden, D. G. A. M., M. Sayab, and M. L. Bouybaouene, 2010: Conjugate-shear folding: A model for the relationships between foliations, folds and shear zones. J. Struct. Geol., 32, 1030-1045, doi: 10.1016/j. jsg.2010.06.010. [Link]

Alsop, G. I. and R. E. Holdsworth, 1999: Vergence and facing patterns in large-scale sheath folds. J. Struct. Geol., 21, 1335-1349, doi: 10.1016/S0191-8141(99)00099-1. [Link]

Bell, T. H., A. P. Ham, and K. A. Hickey, 2003: Early formed regional antiforms and synforms that fold younger matrix schistosities: Their effect on sites of mineral growth. Tectonophysics, 367, 253-278, doi: 10.1016/s0040-1951(03)00126-4. [Link]

Brogi, A., 2006: Foliation relationships and structural facing vs. vergence determinations in refolded lowgrade metamorphic rocks: An example from the Tuscan Metamorphic 'Basement' (Northern Apennines, Italy). J. Struct. Geol., 28, 115-128, doi: 10.1016/j. jsg.2005.07.009. [Link]

Chen, P. Y., 1963: Mineralogy and petrology of the chloritoid rock from Shakatangchi and Laohsichi area, Hualien, Taiwan. Acta Geol. Taiwan., 10, 11-28.

Chen, W. M. and C. N. Yang, 1985: Structure of the Tananao schist in the Tungmen area, Hualien, Taiwan. Ti-Chih, 6, 1-20.

Faure, M. and B. Natal'in, 1992: The geodynamic evolution of the eastern Eurasian margin in Mesozoic times. Tectonophysics, 208, 397-411, doi: 10.1016/0040-1951-
(92)90437-B. [Link]

Ham, A. P. and T. H. Bell, 2004: Recycling of foliations during folding. J. Struct. Geol., 26, 1989-2009, doi: 10.1016/j.jsg.2004.04.003. [Link]

Ho, G. R., 2007: A study of geological structure in the Wanrung area, Central Range, Taiwan. Master Thesis, National Cheng Kung University, Taiwan.

Jiao, Z. H., 1991: The geologic structure and evolution of the Hoping area in eastern Taiwan. Master Thesis, National Taiwan University, Taiwan.

Johnson, S. E. and R. H. Vernon, 1995: Inferring the timing of porphyroblast growth in the absence of continuity between inclusion trails and matrix foliations: Can it be reliably done? J. Struct. Geol., 17, 1203-1206, doi: 10.1016/0191-8141(95)00021-5. [Link]

Lagarde, J.L. and A. Michard, 1986: Stretching normal to the regional thrust displacement in a thrust-wrench shear zone, Rehamna Massif, Morocco. J. Struct. Geol., 8, 483-492, doi: 10.1016/0191-8141(86)90065-9. [Link]

Lan, C. Y., C. S. Lee, T. F. Yui, H. T. Chu, and B. M. Jahn, 2008: The tectono-thermal events of Taiwan and their relationship with SE China. Terr. Atmos. Ocean. Sci., 19, 257-278, doi: 10.3319/TAO.2008.19.3.257(TT). [Link]

Lan, C. Y., T. Usuki, K. L. Wang, T. F. Yui, K. Okamoto, Y. H. Lee, T. Hirata, Y. Kon, Y. Orihashi, J. G. Liou, and C. S. Lee, 2009: Detrital zircon evidence for the antiquity of Taiwan. Geosci. J., 13, 233-243, doi: 10.1007/ s12303-009-0023-3. [Link]

Lee, C. S., 1984: Stratigraphic study of the Tananao group in the region north of the Liwuchi, Taiwan. Cent. Geol. Surv., 3, 1-10.

Lee, Y. H., 1997: Structural evolution of middle section of Central Range, Taiwan. Master Thesis, National 
Taiwan University, Taiwan, 246 pp.

Lin, M. L., 1986: Petrotectonic study on the Yuli belt of Tananao schist in the Chinshuichi area, Yuli, Hualien, Taiwan. Ph.D. Thesis, National Taiwan University, Taiwan.

Lin, M. L., C. N. Yang, and Y. Wang, 1984: Petrotectonic study on the Yuli belt of the Tananao schist in the Chinshuichi area, Eastern Taiwan. Acta Geol. Taiwan., 22, 151-188.

Liotta, D., 2002: $D_{2}$ asymmetric folds and their vergence meaning in the Montagnola Senese metamorphic rocks (inner northern Apennines, central Italy). J. Struct. Geol., 24, 1479-1490, doi: 10.1016/S0191-8141(01)00145-6. [Link]

Lo, W., 1993: Geologic map and explanatory text of Taiwan 27 Tayulin. Geological Map of Taiwan Scale 1:50,000, Central Geological Survey, Ministry of Economic Affairs, Taiwan, 1-64.

Maher, H. D. Jr., 1994: The role of extension in mountainbelt life cycles. J. Geosci. Educ., 42, 212-219.

Malavieille, J., 1993: Late Orogenic extension in mountain belts: Insights from the basin and range and the Late Paleozoic Variscan Belt. Tectonics, 12, 1115-1130, doi: 10.1029/93TC01129. [Link]

McClay, K. R., 1987: The Mapping of Geological Structures, Wiley-Blackwell, $168 \mathrm{pp}$.

Ogasawara, M., Y. Siba, H. Ichihara, and T. Suzuki, 1936: Kenkai. Geological map of Taiwan and explanatory text scale 1:100,000.

Ponce, C., E. Druguet, and J. Carreras, 2013: Development of shear zone-related lozenges in foliated rocks. J. Struct. Geol., 50, 176-186, doi: 10.1016/j.jsg.2012.04.001. [Link]

Powell, D., 1992: Interpretation of Geological Structures Through Maps: An Introductory Practical Manual, Longman Group United Kingdom, 192 pp.

Stanley, R. S., L. B. Hill, H. C. Chang, and H. N. Hu, 1981: A transect through the metamorphic core of the Central Mountains, southern Taiwan. Mem. Geol. Soc. China, 4, 443-473.

Tobisch, O. T. and S. R. Paterson, 1988: Analysis and interpretation of composite foliations in areas of progressive deformation. J. Struct. Geol., 10, 745-754, doi: 10.1016/0191-8141(88)90081-8. [Link]
Turner, F. J. and L. E. Weiss, 1963: Structural Analysis of Metamorphic Tectonites, McGraw-Hill, New York, $545 \mathrm{pp}$.

Wang, C. M., 1982: "The Tananao schist", reinterpreted. Proc. Geol. Soc. China, 25, 5-12.

Wang, C. M. and C. Y. Lu, 1981: Structure of the Tananao schist between Lo-Shao and Tzemuchiao, eastern Taiwan. Ti-Chih, 3, 121-133.

Wang, Y. and C. N. Yang, 1979: Evidences for Polymetamorphism and multiple deformation in the Tananao schist. Ti-Chih, 2, 39-45.

Williams, P. F. and R. Compagnoni, 1983: Deformation and metamorphism in the Bard area of the Sesia Lanzo Zone, Western Alps, during subduction and uplift. $J$. Metamorph. Geol., 1, 117-140, doi: 10.1111/j.15251314.1983.tb00268.x. [Link]

Yang,Z. N., 1981: Petrotectonic study on the Tananao schist in the Juisui area, Hualien, Taiwan. Ph.D. Thesis, National Taiwan University, Taiwan, 58 pp.

Yeh, E. C., 2004 : Structural evolution of slate belts examples from Taiwan and eastern Pennsylvania. Ph.D. Thesis, Pennsylvania State University, United States.

Yen, T. P., 1960: A stratigraphical study on the Tananao schist in northern Taiwan. Bull. Geol. Sur. Taiwan, 12, 53-66.

Yen, T. P., 1963: The metamorphic belts within the Tananao schist terrain of Taiwan. Proc. Geol. Soc. China, $\mathbf{6}$, 72-74.

Yui, T. F., K. Okamoto, T. Usuki, C. Y. Lan, H. T. Chu, and J. G. Liou, 2009: Late Triassic-Late Cretaceous accretion/subduction in the Taiwan region along the eastern margin of South China - evidence from zircon SHRIMP dating. Int. Geol. Rev., 51, 304-328, doi: 10.1080/00206810802636369. [Link]

Yui, T. F., K. Maki, C. Y. Lan, T. Hirata, H. T. Chu, Y. Kon, T. D. Yokoyama, B. M. Jahn, and W. G. Ernst, 2012: Detrital zircons from the Tananao metamorphic complex of Taiwan: Implications for sediment provenance and Mesozoic tectonics. Tectonophysics, 541-543, 3142, doi: 10.1016/j.tecto.2012.03.013. [Link]

Zhan, Y. Z., 1990: Ductile shear structures from the Hojen to Sanchan area on the eastern flank of the Central Range, Taiwan. Master Thesis, National Taiwan University, Taiwan, 85 pp. 